\title{
Peran nance holding arch dalam perawatan ortodonti kasus maloklusi kelas I dengan overjet besar
}

\author{
Erlina Hasriati ${ }^{1 *}$, Haru Setyo Anggani ${ }^{1}$ \\ ${ }^{1}$ Departemen Ortodonti, Fakultas Kedokteran Gigi Universitas Indonesia, Indonesia
}

*Korespondensi: dra.erlina@gmail.com

Submisi: 20 Mei 2020; Penerimaan: 27 November 2020; Publikasi online: 30 November 2020

ABSTRAK

DOI: $\underline{10.24198 / \mathrm{jkg} . v 32 \mathrm{i} 1.27467}$

Pendahuluan: Gigi yang protrusif dan berjejal parah sangat mempengaruhi estetika wajah seseorang, oleh karena itu kondisi ini perlu diatasi secara ortodonti karena dapat mempengaruhi kepercayaan diri dan kualitas hidup seseorang terutama wanita. Selain kebutuhan ruang, perawatan ortodonti yang dilakukan haruslah juga memperhatikan-kontrol penjangkaran yang optimal. Tujuan laporan kasus ini menyampaikan penatalaksanaan perawatan ortodonti maloklusi kelas I dengan overjet besar Laporan kasus: Seorang pasien wanita usia 25 tahun datang ke Klinik Spesialis Ortodonti RSKGM FKG UI untuk mendapatkan perawatan ortodonti karena kondisi giginya yang sangat protusif. Secara klinis diketahui bahwa pasien memiliki maloklusi kelas I dengan overjet $10 \mathrm{~mm}$. Perawatan ortodonti dilakukan menggunakan breket preadjusted sistem MBT slot.022 serta penjangkaran NHA. Simpulan: Hasil perawatan menunjukkan senyum pasien yang lebih estetik dengan inklinasi gigi anterior dan overjet yang terkoreksi dengan baik. NHA bermanfaat sebagai penambah penjangkaran pada kasus overjet besar yang membutuhkan penjangkaran maksimum, sehingga dapat dijadikan alternatif pilihan alat penambah penjangkaran dalam perawatan ortodonti cekat.

Kata Kunci: Protrusif, nance holding arch (NHA), overjet besar.

\section{The role of nance holding arch in orthodontic treatment of class I malocclusion case with large overjet}

\section{ABSTRACT}

Introduction: Protrusive teeth and severe congestion highly affect the face aesthetical aspects; therefore, this condition needs to be treated orthodontically because it can affect the self-confidence and quality of life, especially in women. In addition to space requirements, orthodontic treatment must also pay attention to optimal anchoring control. The purpose of this case report was to deliver the management of class I malocclusion orthodontic with a large overjet. Case report: A 25-years-old female patient came to the Orthodontic Specialist Clinics of University of Indonesia Dental Hospital to get orthodontic treatment because of very protrusive teeth. From the clinical examination, the patient has a class I malocclusion with a $10 \mathrm{~mm}$ overjet. Orthodontic treatment was performed using pre-adjusted brackets with MBT slot .022 system and NHA anchoring. Conclusion: The treatment result showed a more aesthetic smile of the patient with well corrected anterior tooth inclination and overjet. NHA is useful as an anchoring enhancer in large overjet cases which require maximum anchoring so that it can be used as an alternative anchor enhancement tool in fixed orthodontic treatment.

Keywords: Protrusive, nance holding arch (NHA), large overjet. 


\section{PENDAHULUAN}

Kondisi gigi yang berjejal dan protusif dapat mempengaruhi kepercayaan diri dan kualitas hidup seseorang terutama bagi wanita karena mengakibatkan tampilan senyum yang tidak estetis. Hal ini terbukti dalam penelitian yang dilakukan oleh Jung et al' bahwa kelompok pasien wanita yang memiliki kasus gigi berjejal dan overjet besar yang parah, memiliki kepercayaan diri dan kualitas hidup lebih buruk dibandingkan dengan kelompok yang memiliki kondisi gigi berjejal tetapi protusif ringan atau overjet tidak terlalu besar. Hal ini dibuktikan juga pada beberapa penelitian bahwa perawatan ortodontik berhasil secara bermakna mempengaruhi status psikososial pasien dan meningkatkan kualitas hidup seorang pasien terutama yang memiliki masalah dental yang kurang estetis. ${ }^{2-4}$

Gigi anterior yang protusif dengan overjet yang besar merupakan salah satu bentuk maloklusi yang sangat mempengaruhi senyum dan penampilan wajah. Penatalaksanaan kasus maloklusi kelas I overjet besar memerlukan rencana perawatan yang tepat agar didapatkan hasil yang maksimal. Salah satu yang paling menentukan hasil akhir perawatan adalah kontrol penjangkaran.

Koreksi overjet besar, dengan retraksi gigi anterior atas memerlukan penjangkaran maksimum, karena penutupan ruang dilakukan dengan retraksi segmen anterior semaksimal mungkin, serta mencegah pergerakan segmen posterior. Penjangkaran maksimum dikatakan dapat dicapai bila digunakan alat penambah pejangkaran. Terdapat beberapa macam alat penambah penjangkaran yang digunakan untuk memberikan efek penjangkaran maksimum salah satunya yang sering digunakan adalah Nance Holding Appliance (NHA).

Nance Holding Appliance (NHA) merupakan alat penjangkaran tambahan yang bersifat tissue-borne dan telah diperkenalkan sejak tahun 1947 oleh Hayes Nance. Beberapa laporan kasus menunjukkan bahwa NHA efektif sebagai penambah penjangkaran, sehingga dapat mengurangi risiko terjadinya loss of anchorage pada kasus yang memerlukan seluruh ruangan paska pencabutan bagi penatalaksanaan kasus overjet besar atau protusi berat. NHA memiliki berapa keunggulan dibandingkan alat penambah penjangkaran lainnya, antara lain adalah efektifitasnya tidak dipengaruhi oleh kepatuhan pasien dan cukup ekonomis. ${ }^{5-7}$ Namun kekurangan NHA adalah kurang nyaman dipakai karena adanya plat akrilik di palatum. Pembersihan oral hygiene di sekitar dan di bawah pelat akrilik NHA pun agak sulit. Hal ini meningkatkan risiko terjadinya inflamasi pada mukosa di bawah plat akrilik NHA. ${ }^{8}$

Tujuan laporan kasus ini menyampaikan penatalaksanaan perawatan ortodonti maloklusi kelas I dengan overjet besar.

\section{LAPORAN KASUS}

Pasien perempuan 25 tahun, datang ke Klinik Spesialis Ortodonti Rumah Sakit Kesehatan Gigi dan Mulut Fakultas Kedokteran Gigi Universitas Indonesia (RSKGM FKG UI) dengan keluhan gigi maju sehingga sulit menutup mulut serta tidak beraturan. Pasien merasa malu dengan penampilan senyumnya dan merasa terganggu karena kesulitan menutup mulut sehingga air liurnya selalu membasahi bantal saat sedang tidur. Pasien telah menyetujui kasusnya dipublikasikan dengan menandatangani informed consent.

Gambaran klinis ekstraoral, terlihat pasien memiliki wajah brachyfacial, simetris, dan seimbang. Dagu dan profil jaringan lunak lurus (tangent line: $8^{\circ}$ ). Bibir pasien potentially competent dengan sudut nasolabial $80^{\circ}$ (gambar 1). Gambaran klinis intraoral menunjukkan kebersihan mulut pasien cukup baik, kesehatan gingiva cukup baik, serta tidak ditemukan adanya gigi yang goyang. Pasien memiliki palatum yang dalam dan lidah berukuran sedang. Terdapat tambalan sementara pada gigi 11.

Gigi anterior atas terlihat protusif, dengan jarak gigit (overjet) $10 \mathrm{~mm}$ dan tumpang gigit (overbite) $4 \mathrm{~mm}$. Hubungan molar pertama tetap kanan dan kiri kelas I. Hubungan kaninus kanan dan kiri kelas II cusp to cusp. Selain itu terlihat adanya gigitan silang di regio gigi-gigi premolar kanan dan kiri. Lengkung gigi atas berjejal ringan dan lengkung gigi bawah juga berjejal ringan pada segmen anterior namun pada segmen posterior terdapat gigi premolar kedua kanan dan kiri yang malposisi ke bukal hingga keluar dari lengkung gigi. Midline lengkung gigi atas segaris dengan garis wajah dan midline lengkung gigi bawah bergeser $1 \mathrm{~mm}$ ke kanan. Curve of spee dalam, 
yaitu $5 \mathrm{~mm}$ pada sisi kanan dan $6 \mathrm{~mm}$ pada sisi kiri. Bentuk lengkung gigi atas oval dan bentuk lengkung gigi bawah persegi. Terdapat gigi 48 dan
38 yang impaksi.

Pemeriksaan fungsional menunjukkan tidak adanya kelainan pada sendi temporomandibular.
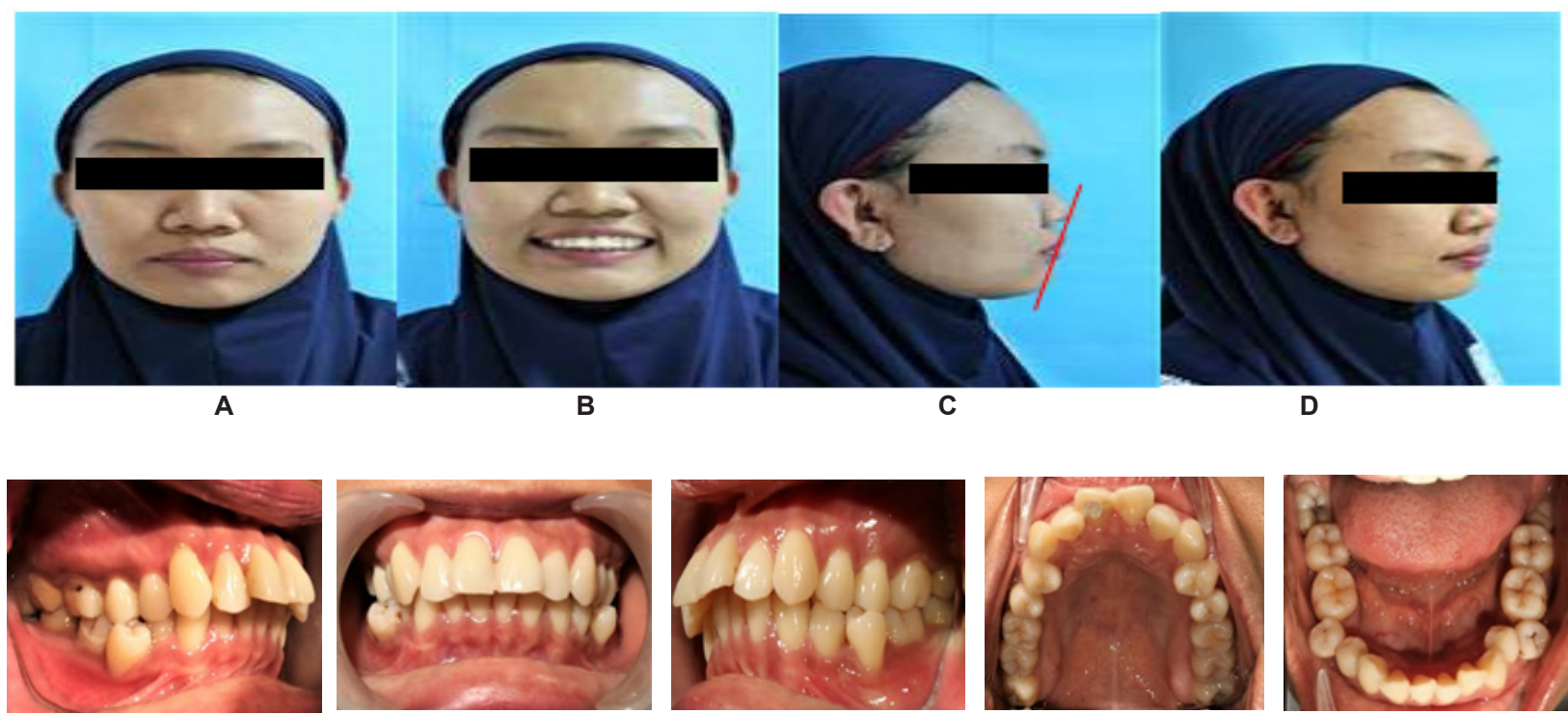

Gambar 1. Foto ekstraoral sebelum perawatan ortodonti: A.Frontal; B.Senyum; C.Profil; D.Samping. Foto intraoral sebelum perawatan ortodonti: E.Lateral kanan; F.Frontal; G.Lateral kiri; H.Atas; I.Bawah. (sumber: dokumentasi pribadi)

Tidak terdapat deviasi pada saat gerakan buka tutup mulut, serta tidak terdapat vertikal interference. Hasil pemeriksaan klinis dan anamnesis juga menunjukkan pada pasien ini tidak terdapat kelainan pada pola penelanan, pernapasan dan pengucapan. Pasien juga tidak memiliki kebiasaan buruk yang dapat mempengaruhi kondisi maloklusi.

Gambaran panoramik menunjukkan adanya gigi 48 dan 38 impaksi. Kondilus kanan dan kiri simetris. Terlihat penurunan ketinggian tulang alveolar $1 / 3$ servikal regio posterior bawah.
Hasil analisis sefalometri lateral menunjukkan Hubungan skeletal kelas I (ortognati) dengan maksila dan mandibula normal terhadap basis kranii. Profil skeletal lurus. Pertumbuhan vertikal $1 / 3$ muka bawah normal cenderung hipodivergen. Inklinasi insisif atas protusif terhadap insisif bawah, basis kranii, dan bidang maksila. Inklinasi insisif bawah protusif terhadap bidang mandibula. Bibir atas dan bawah terlihat maju terhadap garis $E$-line.

Diagnosis kasus ini adalah maloklusi kelas 1 dengan protusi anterior dan overjet $10 \mathrm{~mm}$ disertai
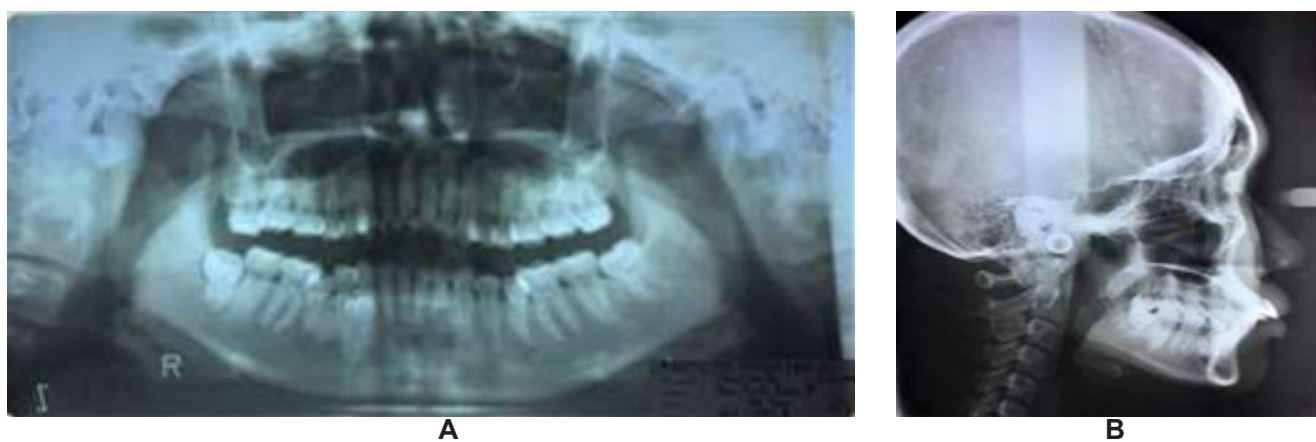

Gambar 2. Gambaran radiografik: A. Panoramik ; B. Sefalometri lateral

crowding pada lengkung gigi atas dan bawah. Kasus ini memiliki prognosis yang baik karena maloklusi bersifat dentoalveolar tanpa disertai adanya kelainan skeletal maupun kebiasaan buruk yang dapat mempengaruhi hasil perawatan ortodonti. Hasil analisis perhitungan ruang yang dibutuhkan untuk mengatasi maloklusi pada kasus ini adalah sebesar $8 \mathrm{~mm}$ pada sisi kanan dan $7 \mathrm{~mm}$ pada sisi kiri lengkung gigi atas, serta masing-masing $6 \mathrm{~mm}$ pada sisi kanan dan kiri pada 
lengkung gigi bawah. Hasil analisis perhitungan ruang tersebut menunjukkan bahwa kasus ini memiliki indikasi pencabutan di kedua lengkung gigi guna mendapatkan ruangan. Penambah penjangkaran dibutuhkan di kedua lengkung gigi agar seluruh ruangan bekas pencabutan gigi- gigi premolar tersebut dapat sepenuhnya dipakai untuk mengkoreksi overjet besar.

Posisi gigi- gigi di regio posterior dipertahankan agar tidak bergerak ke mesial dengan menggunakan NHA. Gigi premolar pertama rahang atas kanan kiri pada kasus ini menjadi pilihan sebagai gigi yang diekstraksi, karena posisinya yang strategis dalam menyediakan ruang untuk koreksi overjet besar dan crowding. Gigi premolar kedua menjadi pilihan gigi yang diekstraksi pada lengkung gigi bawah karena mempertimbangkan posisinya yang bukoversi. Perawatan ortodonti pada kasus ini menggunakan breket preadjusted sistem MBT dengan slot 022 dan Nance Holding Appliance (NHA) sebagai alat penambah penjangkaran. NHA merupakan modifikasi dari Transpalatal Arch (TPA) yang terdiri dari kawat round stainless steel $0.9 \mathrm{~mm}$ yang diwelding/disolder ke molar band dan dihubungkan dengan pelat akrilik yang diposisikan pada bagian anterior lekukan terdalam palatal vault.Perawatan diawali dengan ekstraksi yang dilanjutkan dengan pemasangan NHA dan pemasangan kawat segmental SS $.016 \times .022$ pada regio posterior rahang atas dan bawah untuk distalisasi kaninus rahang atas dan premolar pertama rahang bawah. Hal ini dilakukan untuk memperkuat penjangkaran di posterior, membuka ruang untuk koreksi crowding anterior, dan mencegah gigi anterior semakin protusif saat tahap aligning dan leveling.

Retraksi anterior rahang atas yang dilakukan pada kasus ini dilakukan dengan dua tahap yaitu retraksi kaninus terlebih dahulu dilanjutkan dengan retraksi empat gigi anterior. Retraksi empat gigi anterior dilakukan pada kawat SS.017 X .025 dengan step-up pada segmen anterior untuk mengkompensasi ekstrusi yang terjadi saat retraksi dan mencegah terjadinya deepbite.Setelah 15 bulan perawatan, sasaran perawatan pada umumnya sudah tercapai.

Hasil perawatan secara sefalometri dapat dilihat pada tabel 1 . Sudut I-SN terkoreksi dari
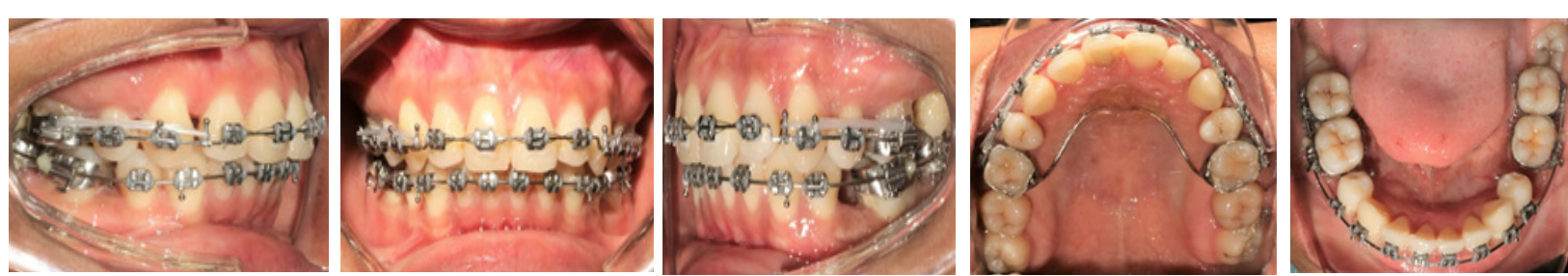

Gambar 3. Foto intraoral kontrol bulan ke-9 tahap retraksi gigi anterior rahang atas: A. Lateral kanan; B. Frontal, step-up kawat dari gigi 12-22; C.Lateral kiri; D.Atas, NHA terpasang; E. Bawah. (sumber: dokumentasi pribadi)

$126^{\circ}$ menjadi $104^{\circ}$. Sedangkan sudut interinsisal juga menjadi normal $129^{\circ}$ dari sudut awalnya $110^{\circ}$. Sudut UI-PP juga menjadi normal $115^{\circ}$ dari sudut awal sebesar $135^{\circ}$. Secara klinis overjet pasien terkoreksi dari $10 \mathrm{~mm}$ menjadi $4 \mathrm{~mm}$, dan overbite dari $4 \mathrm{~mm}$ menjadi $3 \mathrm{~mm}$. Hubungan kaninus pun mengalami perubahan dari kelas 2 menjadi kelas 1. Midline lengkung gigi atas dan bawah segaris dengan midline wajah. Curve of spee pada pasien ini juga membaik, menjadi lebih datar. Hasil akhir perawatan pada lengkung gigi bawah menunjukkan terjadinya intrusi gigi anterior rahang bawah. Secara sefalometri, inklinasi gigi insisif bawah tidak mengalami perubahan dengan sudut Li-MP tetap $96^{\circ}$.

Evaluasi ekstraoral pasca perawatan ortodonti, menunjukkan bahwa pasien sudah tidak

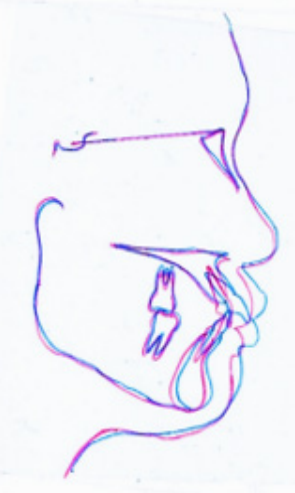

A

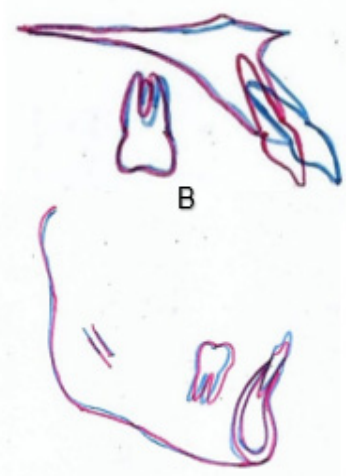

C
Gambar 4. Superimposisi foto sefalometri: A. Fasial lateral pada bidang SN; B.Maksila pada palatal vault; C.Mandibula pada alveolar canal dan kontur bagian dalam dari lempeng kortikal bawah pada simfisis. Warna biru menunjukkan sefalometri sebelum perawatan dan warna merah menunjukkan garis sefalometri setelah perawatan. 


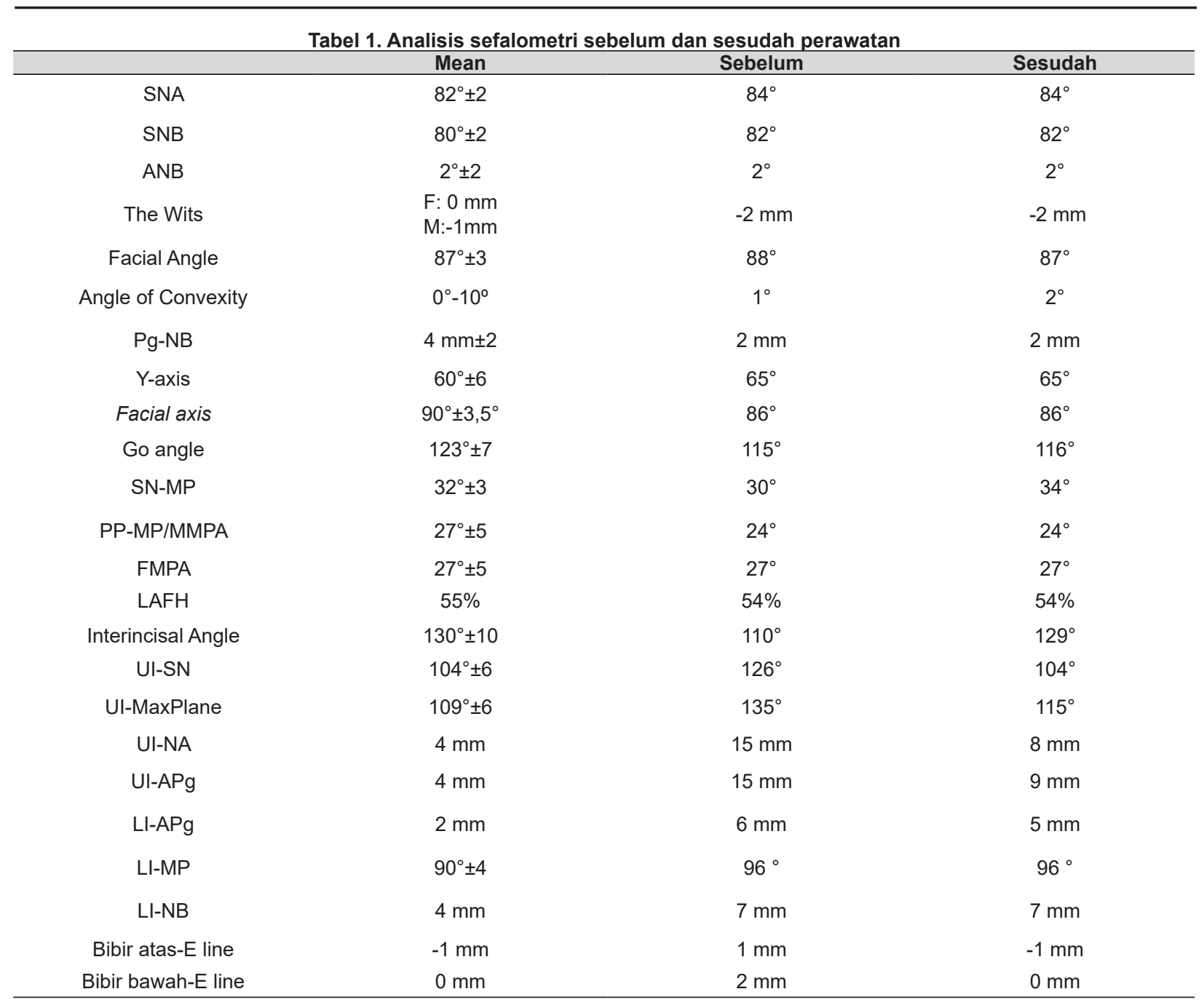

mengalami kesulitan menutup mulutnya dalam keadaan rileks, tidak terlihat ketegangan otot orbicularis oris yang berlebih.

Posisi bibir atas dan bawah terlihat mundur terhadap E-line dengan sudut nasolabial yang normal yaitu $90^{\circ}$. Pasien merasa puas dengan hasil perawatan dan merasa lebih percaya diri.
Perawatan kemudian dilanjutkan dengan tahap retensi menggunakan vacuum formed retainer pada rahang atas dan rahang bawah untuk mempertahankan posisi gigi setelah perawatan ortodontik aktif. Pasien menyetujui kasusnya untuk dipublikasikan dengan menandatangani informed consent.

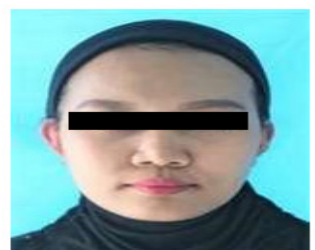

A

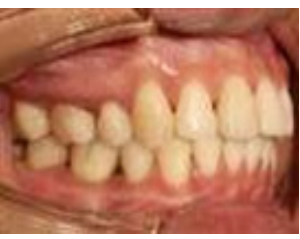

E

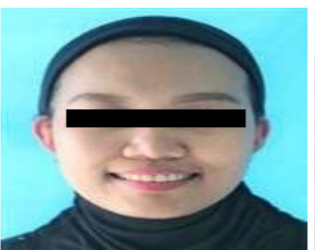

B

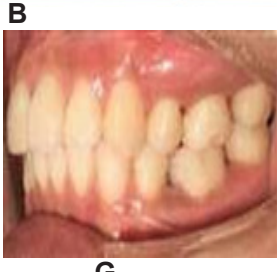

G

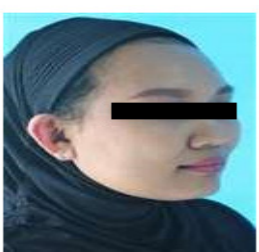

C
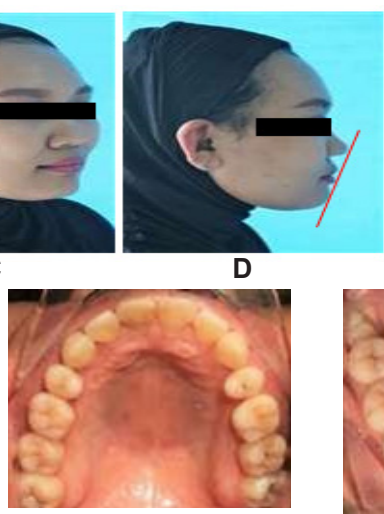

H

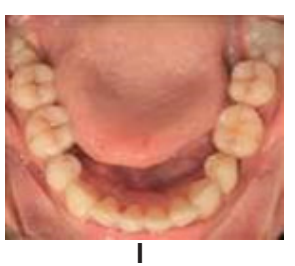

I

Gambar 5. Foto ekstraoral sesudah perawatan ortodonti: A.Frontal; B.Senyum; C.Profil; D.Samping. Foto intraoral sesudah perawatan ortodonti: E.Lateral kanan; F.Frontal; G.Lateral kiri; H.Atas; I.Bawah. (sumber: dokumentasi pribadi) 


\section{PEMBAHASAN}

Keluhan pasien yang utama adalah menyangkut masalah estetika. Pasien merasa kurang percaya diri karena gigi-gigi atasnya terlalu maju dan membuatnya sulit mengatupkan bibir, sehingga pada saat tidur pun air liur mengalir keluar. Hasil anamnesis menunjukkan pasien tidak memiliki kebiasaan buruk terkait kondisi giginya dan diduga maloklusi dipengaruhi faktor genetik karena pasien mengakui orang tua pasien juga memiliki posisi gigi depan yang maju seperti dirinya.

Hasil pemeriksaan ekstraoral menunjukkan pasien masih memiliki profil yang baik namun terlihat kesulitan dalam menutup mulut, sehingga memerlukan aktivitas otot orbicularis oris berlebih untuk mendapatkan lip seal. Hal ini menunjukkan pasien memiliki potentially competent lip akibat posisi gigi anterior rahang atas yang protusif.

Hasil pemeriksaan intraoral menunjukkan permasalahan utama pada pasien ini adalah gigi anterior rahang atas yang protusif, overjet yang besar yaitu $10 \mathrm{~mm}$ disertai crowding pada lengkung gigi atas dan lengkung gigi bawah. Hasil pemeriksaan penunjang analisis sefalometri menunjukkan bahwa pada kasus ini hubungan skeletal normal, sehingga dapat disimpulkan pada kasus ini maloklusi hanya bersifat dental akibat ketidakharmonisan ukuran gigi dengan ukuran rahang yang normal.

Perawatan dilakukan dengan mengurangi material gigi agar didapatkan keharmonisan antara ukuran gigi geligi dengan ukuran lengkung gigi pada rahang. Kombinasi kawat trans palatal dengan pelat akrilik yang terletak pada palatal vault ini dikatakan dapat menambah penjangkaran secara vertikal, transversal, dan anteroposterior. ${ }^{6,9}$

NHA dijadikan pilihan alat penambah penjangkaran dalam kasus ini karena anatomi palatum pasien dapat memberikan dukungan terhadap upaya penjangkaran. Walaupun tidak dapat memberikan penjangkaran absolut, penelitian yang dilakukan Stivaros et $\mathrm{al}^{7}$ dan AlWadhi et $a^{5}$ menunjukkan NHA terbukti efektif sebagai alat penambah penjangkaran pada kasus yang membutuhkan penjangkaran maksimum. NHA juga dijadikan pilihan karena cukup ekonomis bila dibandingkan alat penjangkaran tambahan lainnya, misalnya Temporary Anchorage Device. Kasus ini merupakan kasus dengan indikasi penjangkaran maksimum karena dari perhitungan kebutuhan ruangan sesudah ditentukan rencana perawatannya, diketahui bahwa ruangan yang dibutuhkan adalah $15 \mathrm{~mm}$ di lengkung gigi atas. Kebutuhan ruang yang besar ini mengakibatkan ruang yang didapatkan dari ekstraksi kedua gigi premolar pertama atas harus dipertahankan semaksimal mungkin agar dapat digunakan untuk menghilangkan crowding dan gigi anterior protusif. Mekanoterapi yang digunakan pada kasus ini meliputi beberapa upaya untuk mencegah terjadinya loss of anchorage. Pertama adalah penggunaan Nance Holding Appliance sebagai penambah penjangkaran. Setelah itu diputuskan juga untuk melakukan retraksi gigi-gigi anterior dalam dua tahap, yaitu retraksi gigi kaninus yang dilanjutkan dengan retraksi empat gigi anterior secara en masse disertai intrusi.

Retraksi dua tahap dengan meretraksi gigi kaninus terlebih dahulu diharapkan dapat menjaga penjangkaran segmen posterior saat dilakukan retraksi gigi anterior sehingga mengurangi resiko terjadinya loss of anchorage, walaupun beberapa penelitian menunjukkan bahwa tidak terdapat perbedaan besarnya loss of anchorage antara retraksi en masse dan retraksi dua tahap, ${ }^{10,11}$ namun pada kasus ini retraksi dua tahap dilakukan selain untuk mencegah terjadinya loss of anchorage juga agar didapatkan ruang yang cukup untuk koreksi crowding anterior sehingga menghindari tejadinya flaring gigi anterior saat tahap aligning serta untuk mengontrol pergerakan kaninus agar didapatkan hubungan kaninus kelas I.

Penggunaan NHA pada kasus ini menunjukkan hasil yang memuaskan dalam mencegah pergerakan gigi posterior ke mesial saat retraksi. Kontrol oral hygiene yang baik serta NHA yang segera dilepas setelah retraksi gigi anterior selesai, mampu menjaga kesehatan jaringan lunak palatum tetap terjaga sehingga tidak ada efek samping yang ditimbulkan dari pemakaian NHA.

Kendala yang dihadapi pada kasus ini adalah mempertahankan lengkung gigi bawah saat koreksi crowding dan penutupan ruang agar gigi anterior bawah tidak teretraksi. Sisa ruang pada lengkung gigi bawah ditutup dengan melakukan mesialisasi gigi posterior dan tetap mempertahankan posisi gigi anterior. Inklinasi insisif anterior bawah pada kasus ini tidak dikoreksi untuk menghindari menonjolnya akar insisif bawah pada permukaan bukal serta 
tercapainya overjet yang normal. Kombinasi retraksi dengan penjangkaran maksimum pada rahang atas dan penjangkaran minimum pada rahang bawah menghasilkan overjet yang normal pada kasus ini. Perawatan ortodonti cekat menggunakan breket preadjusted sistem MBT dengan Nance Holding Arch (NHA) terbukti efektif dalam koresi overjet yang parah pada maloklusi kelas I.

\section{SIMPULAN}

Hasil perawatan menunjukkan senyum pasien yang lebih estetik dengan inklinasi gigi anterior dan overjet yang terkoreksi dengan baik. NHA bermanfaat sebagai penambah penjangkaran pada kasus overjet besar yang membutuhkan penjangkaran maksimum, sehingga dapat dijadikan alternatif pilihan alat penambah penjangkaran dalam perawatan ortodonti cekat.

\section{DAFTAR PUSTAKA}

1. Jung $\mathrm{MH}$. An evaluation of self-esteem and quality of life in orthodontic patients: Effects of crowding and protrusion. Angle Orthod. 2015; 85(5): 812-819. DOI: 10.2319/091814.1

2. Johal A, Alyaqoobi I, Patel R, Cox S. The impact of orthodontic treatment on quality of life and self-esteem in adult patients. Eur J Orthod. 2015;37(3):233-237. DOI: 10.1093/ejo/cju047

3. Gazit-Rappaport T, Haisraeli-Shalish M, Gazit E. Psychosocial reward of orthodontic treatment in adult patients. Eur $\mathrm{J}$ Orthod. 2010;32(4):441-446. DOI: 10.1093/ejo/cjp144

4. De Couto Nascimento $V$, De Castro Ferreira Conti AC, De Almeida Cardoso M, Valarelli DP, De Almeida-Pedrin RR. Impact of orthodontic treatment on self-esteem and quality of life of adult patients requiring oral rehabilitation. Angle Orthod. 2016;86(5):839-845. DOI: $\underline{10.2319 / 072215-496.1}$
5. Al-Awadhi EA, Garvey TM, Alhag M, Claffey NM, O'Connell B. Efficacy of the Nance appliance as an anchorage-reinforcement method. Am J Orthod Dentofac Orthop. 2015; 147(3): 330 338. DOI: 10.1016/i.ajodo.2014.11.014

6. Sandler J, Murray A, Thiruvenkatachari B, Gutierrez R, Speight P, O'Brien K. Effectiveness of 3 methods of anchorage reinforcement for maximum anchorage in adolescents: A 3-arm multicenter randomized clinical trial. Am J Orthod Dentofac Orthop. 2014;146(1):10-20. DOI: 10.1016/j.ajodo.2014.03.020

7. Stivaros N, Lowe C, Dandy N, Doherty B, Mandall NA. A randomized clinical trial to compare the Goshgarian and Nance palatal arch. Eur J Orthod. 2010;32(2):171-176. DOI: 10.1093/ejo/cjp075

8. Arikan V, Kizilci E, Ozalp N, Ozcelik B. Effects of fixed and removable space maintainers on plaque accumulation, periodontal health, candidal and enterococcus faecalis carriage. Med Princ Pract. 2015;24(4):311-317. DOI:10.1159/000430787

9. Almuzian M, Alharbi F, Chung LL-K, Mclntyre G. Transpalatal, nance and lingual arch appliances: clinical tips and applications. Orthod Updat. 2017;8(3):92-100. DOI: 10.12968/ortu.2015.8.3.92

10. Felemban N, Hassan A, Murshid Z, AlSulaimani F. En masse retraction versus twostep retraction of anterior teeth in extraction treatment of bimaxillary protrusion. J Orthod Sci. 2013;2(1):28-37. DOI: 10.4103/2278$\underline{0203.110330}$

11. Schneider PP, Júnior LGG, Da Costa Monini A, Dos Santos Pinto A, Kim KB. Comparison of anterior retraction and anchorage control between en masse retraction and two-step retraction: A randomized prospective clinical trial. Angle Orthod. 2019;89(2):190-199. DOI: 10.2319/051518-363.1 